\title{
Headache as anUnusual Presentation of Ischemic Heart Disease: A Case Report
}

\author{
Abdul Wadud Chowdhury ${ }^{1}$, Sudhakar Sarker ${ }^{2}$, Mohammad Ali ${ }^{3}$ Pratyay Hasan ${ }^{4}$, \\ Sazedur Rahman', Md. Rafiqul Islam6, Quazi Deen Mohammad \\ ${ }^{1}$ Professor and Head,Department of Cardiology, Dhaka Medical College, Dhaka, Bangladesh; ${ }^{2}$ Specialist \\ Cardiologist, Bangladesh Specialized Hospital, Shyamoli, Dhaka, Bangladesh; ${ }^{3}$ Specialist Cardiologist, \\ Bangladesh Specialized Hospital, Shyamoli, Dhaka, Bangladesh; ${ }^{4}$ Indoor Medical Officer, Department of \\ Medicine, Dhaka Medical College Hospital, Dhaka, Bangladesh; ${ }^{5}$ Specialist Cardiologist, Bangladesh \\ Specialized Hospital, Shyamoli, Dhaka, Bangladesh; ${ }^{6}$ Specialist Cardiologist, Bangladesh \\ Specialized Hospital, Shyamoli, Dhaka, Bangladesh; ${ }^{7}$ Professor of Neurology \& Director, \\ National Institute of Neurosciences \& Hospital, Dhaka, Bangladesh
}

[Received: 30 October 2018; Accepted: 2 November 2018; Published: 1 January 2019]

\begin{abstract}
The clinical features of coronary artery disease vary, and patients may present with symptoms other than chest pain, such as headache. Rarely, the headache may be theonly presenting feature without any chest discomfort, and may be confused with migraine. Failure to distinguish such headache, caused by CAD, from migraine may result in wrong treatment with disastrous fate. Elderly patient with the presence of cardiovascular risk factors having recent onset exertional headache should be evaluated for the presence of cardiac cephalgia. We intend to report a 60-year-old hypertensive, diabetic patient with a 6-months history of episodic exertional headaches, who turned out to be a case of headache angina (cardiac cephalgia). [Journal of National Institute of Neurosciences Bangladesh, 2019;5(1): 81-86]

Keywords: Headache angina; Cardiac cephalgia; Cardiac cephalalgia

Correspondence: Prof. Dr. Abdul Wadud Chowdhury, Professor and Head, Department of Cardiology, Dhaka Medical College, Dhaka, Bangladesh; Email: drwadud@hotmail.com

Conflict of interest: There is no conflict of interest relevant to this paper to disclose.

Contribution to authors: All authors have contributed from the diagnosis, management and monitoring of the patient.

How to cite this article: Chowdhury AW, Sarker S, Ali M, Hasan P, Rahman S, Islam MR, Mohammad QD. Headache as an Unusual Presentation of Ischemic Heart Disease: A Case Report. J Natl Inst Neurosci Bangladesh, 2019;5(1): 81-86

Copyright: (C2019. Chowdhury et al. Published by Journal of National Institute of Neurosciences Bangladesh. This article is published under the Creative Commons CC BY-NC License (https://creativecommons.org/licenses/by-nc/4.0/). This license permits use, distribution and reproduction in any medium, provided the original work is properly cited, and is not used for commercial purposes.
\end{abstract}

\section{Introduction}

The clinical features of coronary artery disease (CAD) vary, and patients may present withsymptoms other than chest pain1.Patients with CAD who present without chest pain isfrequently misdiagnosed and undertreated. These patients may have pain at othersitessuch asarm, shoulder, back, jaw, or epigastrium. Pain at each of these sites may occur alone or indifferentcombinations ${ }^{1,2}$. Headache as the only symptom of myocardial ischemia is quite rare andthere are only few case reports in the literature on cardiac cephalgia or cephalalgia ${ }^{3,4}$.

\section{Case Presentation}

A 60-year-old hypertensive, diabetic patient presented in September 2018 with a 6-monthshistory of episodic headaches. All attacks occurred only on exertion, initially after walking forabout 10 to $15 \mathrm{~min}$ and later on after walking for just 1 to $2 \mathrm{~min}$. The headache was also provoked byactivities such as lifting heavy objects. The headache was intense, excruciatingin quality, and rated as 9 in severity on the visual analog scale. This intense and excruciating painused to last for 10 to 60 min in each attack. The headache used to subside with complete rest. His routine and social activities were seriously hampered.The pain used to start posteriorly, becoming holocephalic within seconds. On a few occasions, theheadache was associated with nausea, However, there was no vomiting,photophobia, phonophobia, or any aura. He never had any abdominal pain, chest discomfortoratypical chest pain, jaw claudication, or breathlessness associated with exertion or headache.He was diabetic for 10 years and 
hypertensive for 12 years. Neurological examinations were normal; blood pressure was $170 / 90 \mathrm{~mm}-\mathrm{Hg}$. Routinehematological and biochemical investigations were normal. A restingelectrocardiogram (ECG) was within normal limits (Figure I). Echocardiogram showed no regional wallmotion abnormality with good ejectionfraction $(63.0 \%)$. He had undergone magnetic resonanceimaging (MRI) of the brain and cervical spine, which did not reveal any abnormality. Priortreatments with various drugs such as, amitriptyline, valproates, topiramate, flunarizine, paracetamol, indomethacin, and ibuprofen provided no benefit.

In view of exertional-only headache, a possibility of cardiac cephalgia or headache angina was considered.The patient got complete relief from headache within minutes of taking single tablet of sublingual nitroglycerinewhich he described as the best response with any drug. Improvement with nitroglycerine strongly suggestedcardiac cephalgia. During stress test, the patient hadsimilar headache which was associated with $2 \mathrm{~mm}$ depression of ST segment in inferolateral leads. The patient did not feel any chest symptom during stress testing. Headache

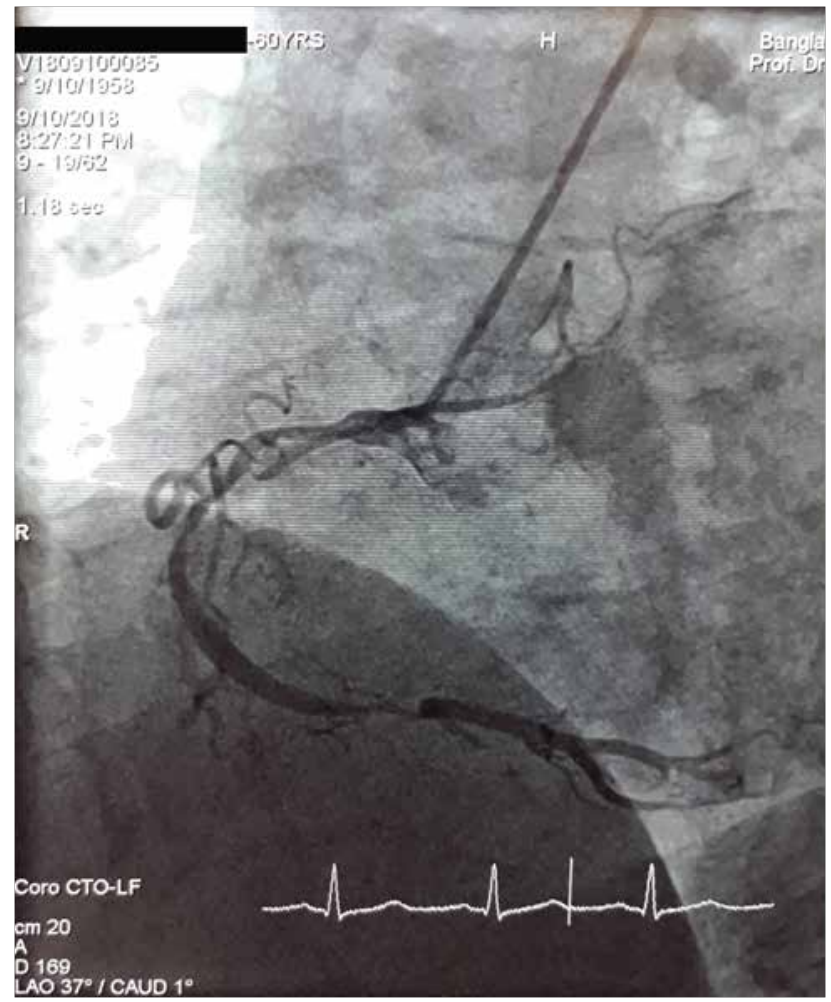

Figure II: Coronary angiogram showing 60 to $70 \%$ stenosis in proximal to mid RCA and another $90 \%$ stenosis in distal RCA

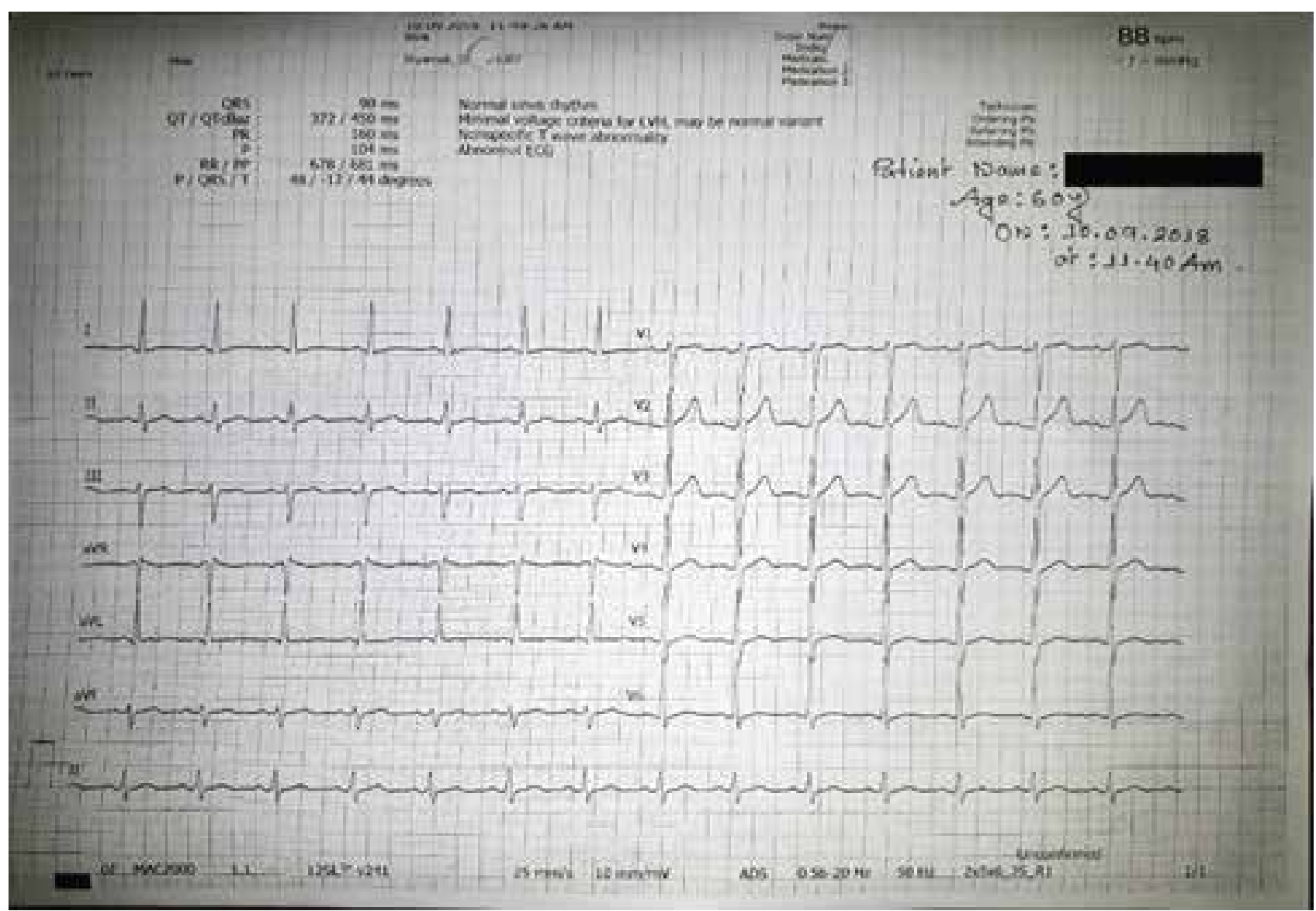

Figure I: Resting 12 lead ECG showed normal findings 


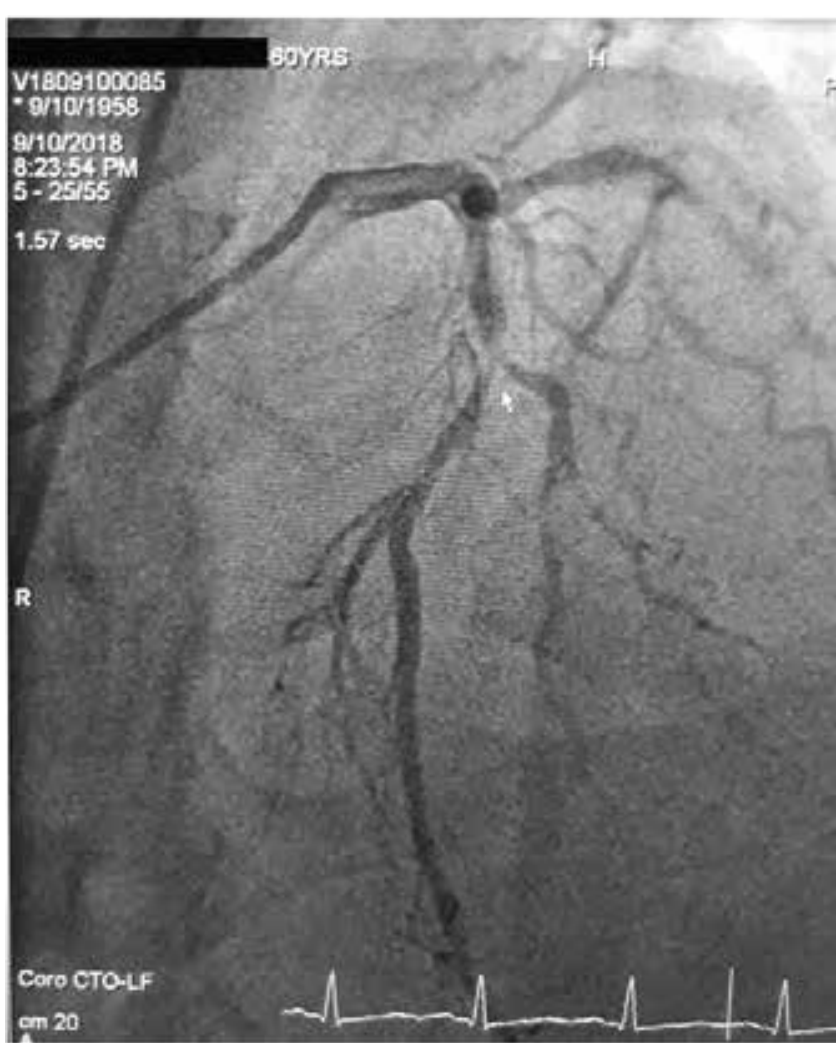

Figure III: Coronary angiogram showing 95.0\% stenosis in mid LAD involving origin of D1

nitroglycerine. On 10th September 2018, a coronary angiogram revealed three vessel disease with $60-70 \%$ stenosis in proximal to mid right coronary artery (RCA), another $90 \%$ stenosis in distal RCA (Figure II), 95\% stenosis in the mid LAD involving D1 (Figure III) and 30 to $40 \%$ stenosis in mid LCX and 80 to $90 \%$ stenosis inprinciple OM (Figure IV). Coronary arterybypass surgery wasdone with 4 grafts. At follow up, two weeks after discharge, the patient was completely symptom free.

\section{Discussion}

An exertional headache has broad differentialdiagnoses, which includes both primary andsecondary headache disorders. Vast majority of exertional headaches are benign. The secondarycauses associated with exertional headaches include space-occupying lesions especially of posterior fossa, vascular abnormalities like aneurysm or arteriovenous malformation, Chiarimalformation, and other obstructions of CSF flow ${ }^{5}$. Cardiac cephalgia is an extremely raretype of exertional headache. There are about 33 cases of cardiac cephalalgia in the literature. Knowledge of cardiac cephalgia and an early diagnosis is important to prevent any catastrophe $\mathrm{s}^{3,4,6}$.

A diagnosis of cardiac cephalgia is made according to

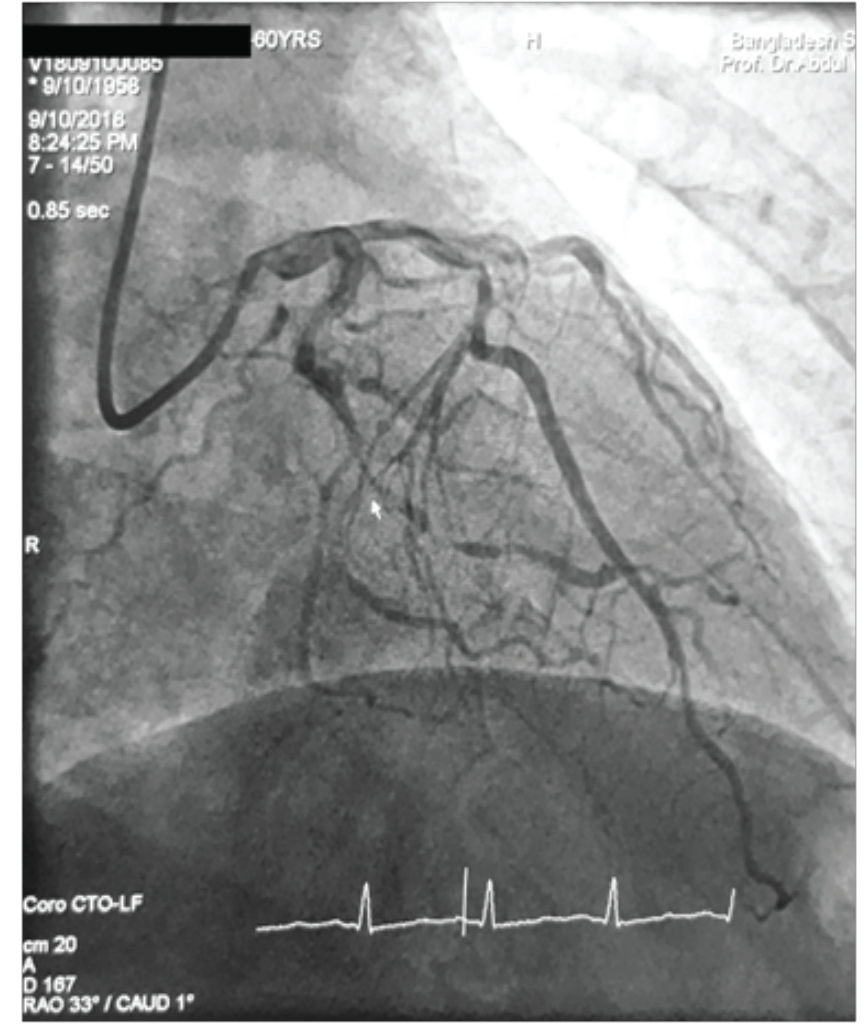

Figure IV:Coronary angiogram showing 30 to $40 \%$ stenosis in the mid LCX and 80 to $90 \%$ stenosis in principal OM

International Classification of Headache Disorders (ICHD)-3 $\beta$ criteria ${ }^{7}$. which depend on the documentation of causation of headache bycardiac ischemia. Evidence of causation is suggested by the presence at least two of the following ${ }^{7}$ : Headache developed in temporal relation to onset of acute myocardial ischemia; Headache worsened with worsening of the myocardial ischemia or headache improvement with improvement in the myocardial ischemia; At least two of the following four characteristics like moderate to severe intensity, accompanied by nausea, not accompanied by photophobia or phonophobia, and aggravated by exertion; and headache is relieved by nitroglycerine or its derivatives. This patient showed all four features.

Approximately $50.0 \%$ of cases of CAD are recognized because of the chest pain ${ }^{8}$. However, chest painmay arise in or radiate to the neck, jaws, tongue, teeth, throat, occiput, cheeks, tip of the nose, ears, shoulders, arms, hands, and to the epigastrium. An exertional headache has broad differential diagnoses, which includes both primary and secondary headache disorders. Vast majority of exertional headaches are benign. The secondary causes associated with exertional headaches include space-occupying lesions especially of posterior fossa, vascular abnormalities 
like aneurysm or arteriovenous malformation, Chiarimalformation, and other obstructions of CSF flow $^{5}$. Cardiac cephalgia is an extremely raretype of exertional headache. There are about 33 cases of cardiac cephalalgia in the literature. Knowledge of cardiac cephalgia and an early diagnosis is important to prevent any catastrophe $\mathrm{e}^{3,4,6}$.

A diagnosis of cardiac cephalgia is made according to International Classification of Headache Disorders (ICHD)-3 3 criteria ${ }^{7}$. which depend on the documentation of causation of headache by cardiac ischemia. Evidence of causation is suggested by the presence at least two of the following ${ }^{7}$ : Headache developed in temporal relation to onset of acute myocardial ischemia; Headache worsened with worsening of the myocardial ischemia or headache improvement with improvement in the myocardial ischemia; At least two of the following four characteristics like moderate to severe intensity, accompanied by nausea, not accompanied by photophobia or phonophobia, and aggravated by exertion; and headache is relieved by nitroglycerine or its derivatives. This patient showed all four features.

Approximately $50.0 \%$ of cases of CAD are recognized because of the chest pain ${ }^{8}$. However, chest painmay arise in or radiate to the neck, jaws, tongue, teeth, throat, occiput, cheeks, tip of the nose, ears, shoulders, arms, hands, and to the epigastrium ${ }^{1,2,8}$. The association of headache withmyocardial infarction was noted in 1971 by Sampson and Cheitlin ${ }^{9}$. They observed that about $6 \%$ patients with CAD had headache with chest pain. Headache as the onlypresenting feature was firstreported by Casky and Spierings ${ }^{10}$. Thereafter, about 33 cases of cardiac cephalgiahave been reported in the literature ${ }^{3,4,6}$.

Our case presented with exertional headaches. Structural intracranial pathology was ruled out byneuroimaging. This case fulfilled the ICHD-3 criteria of cardiac cephalgia ${ }^{9}$. Headache was always exertional and the patient had immediate symptomatic relief with sublingual nitrate. Moreover, he had complete relief by coronary bypass surgery confirming that the pain was cardiac in origin. To the best of our knowledge, this is the secondcase of cardiac cephalgia reported from Bangladesh. The first reported case of headache angina in Bangladesh was by Chowdhury et $\mathrm{al}^{6}$ in 2015.

Most reported cases of cardiac cephalgia had headache as the main presenting feature ${ }^{3,4}$. However, only $27 \%$ patients reported headache as the only manifestation of cardiac ischemia ${ }^{4}$. About 50\%, patients also had mild nonspecific pain in chest, epigastrium, arm or mandible 4 . Cardiac cephalgia may closely mimic migraine. Both cardiac cephalgia and migraineproduce severe exertional headache with autonomic features particularly nausea. Up to $30 \%$ patients with cardiac cephalgja may have cither nausea or vomiting ${ }^{3,4}$. This patients felt nausea on afew occasions, but he denied the presence of any other symptoms. It is extremely important to differentiate cardiac cephalgia with migraine as erroneous use of tryptansmay progress cardiac ischemia. Interestingly, nitroglycerine which induces migraineprovide relief in patients with cardiac cephalgia $^{4,11}$.

Majority of these patients have one or more risk factors for cardiovascular events, such as hypertension, diabetes, smoking, dyslipidemia and positive family history ${ }^{3,4}$. This patient wasdiabetic and hypertensive.

Cardiac pain is mediated by sympathetic and/or parasympathetic vagal fibers. These fibersconverge to the somatic fibers of the various structures of the body. Anginal pain is mediated bysympathetic fibers from $\mathrm{C} 8$ to $\mathrm{T} 5$ in 50 to $60 \%$ of cases, by vagal fibers in 10 to $20 \%$, and through bothneural fibers in 30 to $40 \%{ }^{12}$. These variations in convergence of fibers are largely responsible forthe variation of cardiac pain. If parasympathetic fibers are involved, the patients would get pain inthe neck and head distribution. A recent observation on 326 patients with confirmed myocardialischemia demonstrated increased prevalence of craniofacial pain with inferior wallischemia ${ }^{13}$. It is a well-known fact that symptoms of inferior wall ischemia are mediated by parasympathetic fibers of vagus nerve.

A few other hypotheses have also been suggested to explain the craniofacial pain in CAD. Elevations in intracranial pressure, release of neurochemical mediators, or spasm of cranialvasculatures are few other explanations for the headache in patients with $\mathrm{CAD}^{3,4}$.

Unrecognized myocardial infarction is quite common in the elderly people. About 21.0 to $33.0 \%$ elderlymen and 26.0 to $54.0 \%$ elderly female with myocardial infarction may escape clinical attention ${ }^{14}$. Therefore, it is possible that large number of patients with cardiac cephalgia remain undiagnosed. It can also be speculated that a subset of patient with myocardial ischemia who escape attention may have headache as a sole presentation.

The association of headache with myocardial infarction was noted in 1971 by Sampson and Cheitlin'. They observed that ab out $6 \%$ patients with CAD had 
headache with chest pain. Headache as the onlypresenting feature was firstreported by Casky and Spierings ${ }^{10}$. There after, about 33 cases of cardiac cephalgiahave been reported in the literature ${ }^{3,4,6}$.

Our case presented with exertional headaches. Structural intracranial pathology was ruled out by neuroimaging. This case fulfilled the ICHD-3 criteria of cardiac cephalgia ${ }^{9}$. Headache wasalways exertional and the patient had immediate symptomatic relief with sublingual nitrate. Moreover, he had complete relief by coronary bypass surgery confirming that the pain was cardiac in origin. To the best of our knowledge, this is the secondcase of cardiaccephalgia reported fromBangladesh. The first reported case of headache angina in Bangladesh was by Chowdhury et $\mathrm{al}^{6}$ in 2015.

Most reported cases of cardiac cephalgia had headache as the main presenting feature ${ }^{3,4}$. However, only $27 \%$ patients reported headache as the only manifestation of cardiac ischemia ${ }^{4}$. About $50 \%$, patients also had mild nonspecific pain in chest, epigastrium, arm or mandible ${ }^{4}$. Cardiac cephalgia may closely mimic migraine. Both cardiac cephalgia and migraineproduce severe exertional headache with autonomicfeatures particularly nausea. Up to $30 \%$ patients with cardiac cephalgja may have cither nausea or vomiting ${ }^{3,4}$. This patients felt nausea on afew occasions, but he denied the presence of any other symptoms. It is extremely importantto differentiate cardiac cephalgia with migraine as erroneous use of tryptansmay progress cardiac ischemia. Interestingly, nitroglycerine which induces migraineprovide relief in patients with cardiac cephalgia ${ }^{4,11}$.

Majority of these patients have one or more risk factors for cardiovascular events, such as hypertension, diabetes, smoking, dyslipidemia and positive family history ${ }^{3,4}$. This patient wasdiabetic and hypertensive.

Cardiac pain is mediated by sympathetic and/or parasympathetic vagal fibers. These fibersconverge to the somatic fibers of the various structures of the body. Anginal pain is mediated by sympathetic fibers from C8 to T5 in 50 to $60 \%$ of cases, by vagal fibers in 10 to $20 \%$, and through bothneural fibers in 30 to $40 \%{ }^{12}$. These variations in convergence of fibers are largely responsible forthe variation of cardiac pain. If parasympathetic fibers are involved, the patients would get pain inthe neck and head distribution. A recent observation on 326 patients with confirmed myocardialischemia demonstrated increased prevalence of craniofacial pain with inferior wallischemia ${ }^{13}$. It is a well-known fact that symptoms of inferior wall ischemia are mediated by parasympathetic fibers of vagus nerve.

A few other hypotheses have also been suggested to explain the craniofacial pain in CAD. Elevations in intracranial pressure, release of neurochemical mediators, or spasm of cranialvasculatures are few other explanations for the headache in patients with $\mathrm{CAD}^{3,4}$.

Unrecognized myocardial infarction is quite common in the elderly people. About 21.0 to $33.0 \%$ elderly men and 26.0 to $54.0 \%$ elderly female with myocardial infarction may escape clinical attention ${ }^{14}$. Therefore, it is possible that large number of patients with cardiac cephalgia remain undiagnosed. It can also be speculated that a subset of patient with myocardial ischemia who escape attention may have headache as a sole presentation.

\section{Conclusion}

Diagnosis of cardiac cephalgia is very important. Review of the literature suggest mortality rateof about $12.0 \%$ for cardiac cephalgia. Therefore, it could be suggested that any elderly patients with the presence of cardiovascular risk factor having recent onset exertional headache should be evaluated for the presence of cardiac cephalgia.

\section{References}

1. Brieger D, Eagle KA, Goodman SG, Steg PG, Budaj A, White $\mathrm{K}$, et al. Acute Coronary Syndromes Without Chest Pain, An Underdiagnosed and Undertreated High-Risk Group: Insights from The Global Registry of Acute Coronary Events. Chest. 2004;126(2):461-9

2. Canto JG, Goldberg RJ, Hand MM, Bonow RO, Sopko G, Pepine CJ, et al. Symptom presentation of women with acute coronary syndromes: myth vs reality. Arch Intern Med. 2007;167(22):2405-13

3. Wei J-H, Wang H-F. Cardiac cephalalgia: case reports and review. Cephalalgia Int J Headache. 2008 Aug;28(8):892-6.

4. Bini A, Evangelista A, Castellini P, Lambru G, Ferrante T, Manzoni GC, et al. Cardiac cephalgia. J Headache Pain. 2009 Feb;10(1):3.

5. Alvarez R, Ramón C, Pascual J. Clues in the differential diagnosis of primary vs secondary cough, exercise, and sexual headaches. Headache. 2014 Oct;54(9):1560-2.

6. Chowdhury AW, Saleh MAD, Hasan P, Amin MG, Khan TA, Sabah KMN, et al. Cardiac cephalgia: A headache of the heart. J Cardiol Cases. 2015 May;11(5):139-41.

7. Headache Classification Committee of the International Headache Society (IHS). The International Classification of Headache Disorders, 3rd edition (beta version). Cephalalgia Int J Headache. 2013 Jul;33(9):629-808.

8. Davies SW. Clinical presentation and diagnosis of coronary artery disease: stable angina. Br Med Bull. 2001;59:17-27.

9. Sampson JJ, Cheitlin MD. Pathophysiology and differential diagnosis of cardiac pain. Prog Cardiovasc Dis. 1971 May;13(6):507-31. 
10. Caskey WH, Spierings EL. Headache and heartache. Headache. 1978 Nov;18(5):240-3.

11. de Tommaso M, Libro G, Guido M, Difruscolo O, Losito L, Sardaro M, et al. Nitroglycerin induces migraine headache and central sensitization phenomena in patients with migraine without aura: a study of laser evoked potentials. Neurosci Lett. 2004 Jun 17;363(3):272-5.

12. Meller ST, Gebhart GF. A critical review of the afferent pathways and the potential chemical mediators involved in cardiac pain. Neuroscience. 1992;48(3):501-24.

13. Kreiner M, Alvarez R, Waldenström A, Michelis V, Muñiz R, Isberg A. Craniofacial pain of cardiac origin is associated with inferior wall ischemia. $\mathrm{J}$ Oral Facial Pain Headache. 2014;28(4):317-21.

14. Leening MJG, Elias-Smale SE, Felix JF, Kors JA, Deckers JW, Hofman A, et al. Unrecognised myocardial infarction and long-term risk of heart failure in the elderly: the Rotterdam Study. Heart Br Card Soc. 2010 Sep;96(18):1458-62. 